Acknowledgements: The PredicSpA study was supported by MSD thanks to an unrestricted grant.

Disclosure of Interest: None declared

DOI: 10.1136/annrheumdis-2017-eular.2509

\section{THU0347 IMPACT OF OBESITY ON THE RESPONSE TO TUMOUR NECROSIS FACTOR INHIBITORS IN AXIAL SPONDYLOARTHRITIS}

R. Micheroli ${ }^{1}$, M. Hebeisen ${ }^{2}$, A. Scherrer ${ }^{2}$, L. Wildi ${ }^{1}$, P. Exer ${ }^{3}$, G. Tamborrini ${ }^{4}$, J. Bernhard ${ }^{5}$, B. Möller ${ }^{6}$, P. Zufferey ${ }^{7}$, M.J. Nissen ${ }^{8}$, A. Ciurea ${ }^{1} .{ }^{1}$ University Hospital Zurich; ${ }^{2}$ SCQM, Zurich; ${ }^{3}$ Rheuma-Basel; ${ }^{4}$ UZR, Basel; ${ }^{5}$ Bürgerspital, Solothurn; ${ }^{6}$ Inselspital, Bern; ${ }^{7} \mathrm{CHUV}$, Lausanne; ${ }^{8}$ University Hospital Geneva, Geneva, Switzerland

Background: Few studies have investigated the impact of obesity on response to tumour necrosis factor inhibitors (TNFi) in patients with axial spondyloarthritis (axSpA).

Objectives: To investigate the impact of different Body Mass Index (BMI) categories on TNFi response in a large cohort of patients with axSpA

Methods: Patients within the Swiss Clinical Quality Management cohort were included if they fulfilled the ASAS criteria for axSpA, started a first TNFi after recruitement and had available BMI data as well as a baseline and follow-up visit at 1 year $( \pm 6 \mathrm{mo})(\mathrm{N}=632)$. Patients were categorized according to BMl: normal (BMI 18.5 to $<25$ ), overweight (BMI 25 to 30 ) and obese $(B M I>30)$. We evaluated the proportion of patients achieving the $40 \%$ improvement ASAS criteria (ASAS40) as well as Ankylosing Spondylitis Disease Activity Score (ASDAS) improvement and status scores at 1 year. Patients having discontinued the TNFi were considered non-responders. We controlled for age, sex, HLA-B27, axSpA-type, BASDAI, BASMI, elevated CRP, current smoking and physical exercise in multiple adjusted logistic regression analyses.

Results: In comparison to normal weight and overweight patients, obese individuals were significantly older, had a longer symptom duration and higher BASFI and BASMI levels, while ASDAS levels were comparable between the 3 groups (Table 1). Data to calculate the ASAS40 response was available in 496 patients $(78 \%)$. It was reached by $44 \%, 35 \%$ and $28 \%$ of patients with normal weight, overweight and obesity, respectively, $(p=0.02$; Table 2). A significantly lower odds ratio (OR) for achieving ASAS40 response was found in adjusted analyses in obese patients vs patients with normal BMI (OR $0.30,95 \%$ confidence interval $(\mathrm{Cl}) 0.11-0.73, p=0.01)$. Comparable results were found for the other outcomes assessed. The respective adjusted ASAS40 OR in overweight vs. normal weight patients was $0.69,95 \% \mathrm{Cl} 0.38-1.24, \mathrm{p}=0.22$.

Table 1. Baseline characteristics at start TNFi

\begin{tabular}{lcccc}
\hline Parameter & $\mathrm{N}$ & \multicolumn{3}{c}{ BMl category } \\
\cline { 3 - 5 } & 632 & Normal $(\mathrm{N}=331)$ & Overweight $(\mathrm{N}=202)$ & Obese $(\mathrm{N}=99)$ \\
\hline Male sex, \% & 632 & 54 & $74^{\star}$ & 64 \\
Age, years & 632 & $37.0(11.2)$ & $40.6(11.5)^{\star}$ & $44.2(10.9)^{\star} \#$ \\
Symptom duration, years & 627 & $11.8(10.1)$ & $13.0(11.4)$ & $15.8(11.7)^{\star} \#$ \\
HLA-B27 positive, \% & 579 & 81 & 77 & 72 \\
BASDAI & 552 & $5.3(2.0)$ & $5.7(1.9)^{\star}$ & $5.8(1.8)^{\star}$ \\
ASDAS-CRP & 520 & $3.4(0.9)$ & $3.5(0.9)$ & $3.6(0.9)$ \\
Elevated CRP, \% & 587 & 55 & 49 & 59 \\
BASFI & 558 & $3.6(2.4)$ & $4.2(2.4)^{\star}$ & $4.9(2.6)^{\star}$ \\
BASMI & 541 & $2.0(2.0)$ & $2.2(1.9)$ & $3.0(2.3)^{\star}$
\end{tabular}

${ }^{*} P$ values $<0.015$ compared with patients with normal weight. " $P$ values $<0.015$ compared with patients with overweight. Values are the mean (SD).

Table 2. Unadjusted response rates after 1 year of treatment with a first TNF inhibitor

\begin{tabular}{lccccc}
\hline Outcome & $\mathrm{N}$ & \multicolumn{3}{c}{ BMl category } & \multirow{2}{*}{$P^{*}$} \\
\cline { 3 - 5 } & 496 & Normal $(\mathrm{N}=258)$ & Overweight $(\mathrm{N}=162)$ & Obese $(\mathrm{N}=76)$ & \\
\hline ASAS40 & 496 & 44 & 35 & 28 & 0.02 \\
ASDAS improvement $\geq 1.1$ & 425 & 60 & 46 & 38 & 0.002 \\
ASDAS $<2.1$ & 472 & 56 & 39 & 31 & $<0.001$ \\
ASDAS improvement $\geq 2$ & 425 & 26 & 24 & 14 & 0.14 \\
ASDAS $<1.3$ & 472 & 30 & 15 & 10 & $<0.001$ \\
\hline
\end{tabular}

Values are the \%. ${ }^{*}$ Overall $\mathrm{P}$ value.

Conclusions: Obesity is associated with significantly lower response rates to TNFi in patients with axSpA.

Disclosure of Interest: None declared

DOI: 10.1136/annrheumdis-2017-eular.2703

\section{THU0348 SAFETY AND EFFICACY OF INTRAVENOUS GOLIMUMAB IN ADULT PATIENTS WITH ACTIVE ANKYLOSING SPONDYLITIS: RESULTS THROUGH WEEK 28}

A. Deodhar ${ }^{1}$, J.D. Reveille ${ }^{2}$, D.D. Harrison ${ }^{3}$, L. Kim ${ }^{3}$, K.H. Lo ${ }^{3}$, E. Hsia ${ }^{3,4}$. ${ }^{1}$ Oregon Health \& Science University, Portland; ${ }^{2}$ University of Texas Health Sciences Center, Houston; ${ }^{3}$ Janssen Research \& Development, LLC, Spring House; ${ }^{4}$ University of Pennsylvania School of Medicine, Philadelphia, United States

Objectives: Subcutaneous (SC) golimumab (GLM) is currently approved for adult patients (pts) with RA, PsA, and AS. The GO-ALIVE study was designed to evaluate the safety and efficacy of IV GLM in adult pts with active AS.

Methods: GO-ALIVE is a Phase 3, multicenter, randomized, double-blind, placebo (PBO)-controlled trial. Pts (aged $>18 \mathrm{yrs}$ ) had a diagnosis of definite AS (per modified New York criteria) and BASDAI $\geq 4$, total back pain visual analogue scale $\geq 4$, and CRP $\geq 0.3 \mathrm{mg} / \mathrm{dL}$. Pts were randomized (1:1) to IV GLM $2 \mathrm{mg} / \mathrm{kg}$ at weeks (wks) 0,4 , and every 8 wks or PBO at wks 0,4 , and 12 , with crossover to GLM at wk16. Up to $20 \%$ of pts could have had a prior anti-TNF agent (other than GLM), and up to $10 \%$ of pts could have complete ankylosis of the spine. The primary endpoint was ASAS20 at wk16. Major secondary endpoints were ASAS40, BASDAI50, and change in BASFI score at wk16. Some of the other statistically-controlled assessments were BASMI, and ASAS partial remission. Pts were monitored for adverse events (AEs). Data through wk28 are reported here. Results: 208 pts were randomized and received study agent (PBO: 103; GLM: 105). Baseline demographic and disease characteristics were similar between treatment groups. $78 \%$ of pts were male, mean age was $39 \mathrm{yrs}$; mean disease duration was $5.5 \mathrm{yrs}, 89.9 \%$ were HLA-B27 positive, $5.8 \%$ had complete ankylosis of the spine, $14.4 \%$ used a prior anti-TNF. At wk16, significantly greater proportions of GLM pts vs PBO had ASAS20 (73.3\% vs. $26.2 \%$ ), ASAS40 (47.6\% vs. $8.7 \%$ ), and BASDAI $50(41.0 \%$ vs. $14.6 \%)$ responses (all $p<0.001$; Table). Reductions in BASFI were also significantly greater with GLM. ASAS20 was significantly higher with GLM than PBO as early as wk2 ( $37.1 \%$ vs $19.4 \% ; p=0.005)$. Responses in the GLM group were maintained through wk28. PBO pts who crossed over to GLM at wk16 had improvements in clinical response at wk20 that were maintained through wk28. Through wk16, $23.3 \%$ of PBO pts and $32.4 \%$ of GLM pts had $\geq 1$ $\mathrm{AE}$. Infections were the most common type of AE (PBO, 7.8\%; GLM, 11.4\%). Through wk28, $34.8 \%$ of all GLM-treated pts had $\geq 1 \mathrm{AE}$; nasopharyngitis $(5.4 \%)$ was the most common. Two pts (1.0\%) had SAEs (pancreatitis, $n=1$; pneumonia, $\mathrm{n}=1$ ). Both were randomized to GLM. There were no opportunistic infections, malignancies, or deaths through wk28. The rate of infusion reactions was low $(1.5 \%) .3$ pts treated with GLM had 4 reactions; none was serious or severe.

\begin{tabular}{|c|c|c|}
\hline & Placebo & Golimumab $2 \mathrm{mg} / \mathrm{kg}$ \\
\hline Patients randomized, $\mathrm{n}$ & 103 & 105 \\
\hline \multicolumn{3}{|l|}{ Clinical efficacy } \\
\hline$\overline{\text { ASAS } 20, \mathrm{n}(\%)}$ & $27(26.2 \%)$ & $77(73.3 \%)^{* * *}$ \\
\hline ASAS40, n (\%) & $9(8.7 \%)$ & $50(47.6 \%)^{* * *}$ \\
\hline BASDAI $50, \mathrm{n}(\%)$ & $15(14.6 \%)$ & $43(41.0 \%)^{\text {t. }}$ \\
\hline Change from baseline in BASFI. $\mathrm{n}$ & 98 & 105 \\
\hline mean (SD) & $-0.5(2.0)$ & $-2.4(2.1)^{* * *}$ \\
\hline ASAS partial remission, $\mathrm{n}(\%)$ & $4(3.9 \%)$ & $17(16.2 \%)^{*}$ \\
\hline $\begin{array}{r}\text { Change from baseline in BASMI (linear), } \mathrm{n} \\
\text { mean (SD) }\end{array}$ & $\begin{array}{c}96 \\
-0.1(0.5)\end{array}$ & $\begin{array}{c}100 \\
-0.4(0.6)^{* *}\end{array}$ \\
\hline \multicolumn{3}{|c|}{$\begin{array}{l}\text { "p }<0.01 ; * * p \leq 0.001 \\
\text { ASAS20/40, } \geq 20 \% / 40 \% \text { improvement in ASsessment in Ankylosing Spondylitis } \\
\text { (ASAS) International Working Group criteria; BASDAI, Bath Ankylosing } \\
\text { Spondylitis Disease Activity Index; BASFI, Bath Ankylosing Spondylitis Functional } \\
\text { Index; BASMI, Bath Ankylosing Spondylitis Metrology Index; SD, standard } \\
\text { deviation }\end{array}$} \\
\hline
\end{tabular}

Conclusions: IV GLM $2 \mathrm{mg} / \mathrm{kg}$ was efficacious in reducing the signs and symptoms of AS compared with PBO. GLM was well-tolerated through wk28; the safety profile was consistent with other anti-TNFs, including SC GLM.

Disclosure of Interest: A. Deodhar Grant/research support from: Janssen, Amgen, Abbvie, GSK, Elli Lilly, Novartis, Pfizer, UCB, Consultant for: Janssen, Elli Lilly, Novartis, Pfizer, UCB, J. Reveille Grant/research support from: Janssen Scientific Affairs, LLC., D. Harrison Employee of: Janssen Research \& Development, LLC, L. Kim Employee of: Janssen Research \& Development, LLC, K. H. Lo Employee of: Janssen Research \& Development, LLC, E. Hsia Employee of: Janssen Research \& Development, LLC DOI: 10.1136/annrheumdis-2017-eular.1020

\section{THU0349 METHOTREXATE REDUCES ADALIMUMAB IMMUNOGENICITY IN PATIENTS WITH SPONDYLOARTHRITIS: A RANDOMIZED CLINICAL TRIAL}

E. Ducourau ${ }^{1,2,3}$, T. Rispens ${ }^{4}$, E. Dernis ${ }^{5}$, F. Le Guilchard ${ }^{6}$, L. Andras ${ }^{6}$,

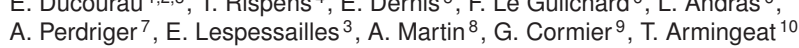
V. Devauchelle-Pensec ${ }^{11}$, E. Solau-Gervais ${ }^{12}$, B. Le Goff ${ }^{13}$, A. de Vries ${ }^{14}$, E. Piver ${ }^{15,16}$, D. Ternant ${ }^{17,18}$, P. Goupille ${ }^{1,2}$, D. Mulleman ${ }^{1,2}{ }^{1}{ }^{1}$ Rheumatology, Université François Rabelais de Tours, CNRS 7292; ${ }^{2}$ Rheumatology, CHRU de Tours, Tours; ${ }^{3}$ Rheumatology, CHR d'Orléans, Orléans, France; ${ }^{4}$ Landsteiner laboratories, Sanquin Research, Amsterdam, Netherlands; ${ }^{5}$ Rheumatology, $\mathrm{CH}$ du Mans, le Mans; ${ }^{6}$ Rheumatology, CH de Blois, Blois; ${ }^{7}$ Rheumatology, CHRU de Rennes, Rennes; ${ }^{8}$ Rheumatology, $\mathrm{CH}$ de Saint-Brieuc, Saint-Brieuc;

${ }^{9}$ Rheumatology, CH de la Roche-sur-Yon, la Roche-sur-Yon; ${ }^{10}$ Rheumatology, $\mathrm{CH}$ de Saint-Nazaire, Saint-Nazaire; ${ }^{11}$ Rheumatology, CHRU de Brest, Brest; ${ }^{12}$ Rheumatology, CHRU de Poitiers, Poitiers; ${ }^{13}$ Rheumatology, CHRU de Nantes, Nantes, France; ${ }^{14}$ Biologicals Lab, Sanquin Diagnostic Services, Amsterdam, Netherlands; ${ }^{15}$ Biochemistry, Université François Rabelais de Tours, Inserm U 966; ${ }^{16}$ Biochemistry, CHRU de Tours; ${ }^{17}$ Pharmacology-Toxicology, Université François-Rabelais de Tours, CNRS 7292; ${ }^{18}$ Pharmacology-Toxicoloy, CHRU de Tours, Tours, France

Background: TNF inhibitors are effective in treating spondyloarthritis (SpA). 